\title{
Correlation of Acoustic Emission with Fractography in Bending of Glass-Epoxy Composites
}

\author{
Maciej Panek ${ }^{1} \cdot$ Stanislaw Blazewicz ${ }^{2} \cdot$ Krzysztof J. Konsztowicz $^{3}$ (D)
}

Received: 30 September 2019 / Accepted: 7 July 2020 / Published online: 16 August 2020

(c) The Author(s) 2020

\begin{abstract}
Damage processes in glass fiber reinforced plastic composites have been examined extensively by many analytical and experimental methods, including acoustic emission. While damage phenomena in mezo- and macro-scale are well described, the subtle mechanisms in micro-scale are still under discussion. The goal of this work was to apply the acoustic emission to examine damage initiation in fiber reinforced epoxy resin composites with different continuous glass-fiber architectures. Basic lay-ups were used: unidirectional, cross-ply and angle-ply, each with varying fiber volume content in epoxy matrix. Detection of fine micro-cracks was possible owing to merging the mechanical monotonic and step-load tests in 4-point bending with acoustic emission monitoring and detailed scanning electron microscopy observations. Clear images of macroscopically undamaged samples after interruption of step-loading cycles revealed the initiation of micro-cracks by debonding of fiber-matrix interfaces, in agreement with acoustic emission signal analyses, featuring use of historic index and rise time/ amplitude ratio.
\end{abstract}

Keywords Micro-crack initiation $\cdot$ Debonding $\cdot$ Acoustic emission $\cdot$ Historic index $\cdot$ Step-load

\section{Introduction}

The mechanical properties of fiber reinforced plastic (FRP) composites have been examined thoroughly in various loading and environmental conditions, following the increasing application needs [1]. Testing methods of mechanical properties of materials may not assure sufficient insight into microstructural details of damage process, in particular the

Krzysztof J. Konsztowicz

kkonsztowicz@ath.bielsko.pl

Maciej Panek

maciej.panek@pwr.edu.pl

Stanislaw Blazewicz

blazew@agh.edu.pl

1 Department of Mechanics, Materials and Biomedical Engineering, Wroclaw University of Science and Technology, ul. Smoluchowskiego 25, 50-372 Wroclaw, Poland

2 Faculty of Materials Sci. and Ceramics, AGH University of Science and Technology, 30-059 Krakow, Poland

3 Department of Matl's, Civil and Environm. Eng., ATH University of Bielsko-Biala, ul. Willowa 2, 43-309 Bielsko-Biala, Poland stage of failure initiation. Monotonic testing methods mostly provide information related to final rupture of material with defined microstructure. Dynamic (fatigue) loading tests deliver more details concerning damage progression, also provide important data on materials' life-span within given stress limits, however do not indicate accurately enough the stress level where the first micro-cracks initiate [2].

Microscopic observations performed on fracture surfaces after mechanical testing are typically "post mortem" analyses, informative of material's state after failure, with no answers concerning micro-mechanisms of damage initiation and evolution [3]. To assist mechanical testing, various non-destructive evaluation (NDE) techniques are used, including acoustic emission [4]. As a result, basic mechanisms of structural degradation of fibrous composites were recognized as matrix cracking, fiber debonding, fiber pullout, fiber breakage and delamination. Depending on loading conditions, these mechanisms may occur in various time related sequences during materials failure. The most often reported damage sequence of fiber composites is "transverse cracking—delamination-fiber failure" [5].

In such description the role of fiber debonding in composite damage is not quite clearly defined. Also the term "matrix cracking" may cover a broad range of physical phenomena 
[6]. It may mean singular micro-cracks formed within continuous matrix materials, and such micro-defects have been observed experimentally during examination of neat epoxy resin samples in loading stages before mechanically registered failure [7]. However, by "common wisdom", this term of matrix cracks is often synonymously referred to large transverse cracks in plies with off-line fibers, appearing in cross-ply composites at noticeable strains [8].

High sensitivity of AE promises good potential for detailed discrimination of damage mechanisms [9]. Due to complexity of $\mathrm{AE}$ wave propagation in anisotropic composites, signals transmitted to processing software may contain only limited representation of real damage sources, yet still considered sufficient for further analytical treatment [10]. Since various damage mechanisms may occur almost simultaneously in loaded composites, the classification of often large number of $\mathrm{AE}$ signals and assigning a specific set of AE signal characteristics to a peculiar damage mechanism remains a scientific challenge, currently solved with use of pattern recognition techniques [11].

After $\mathrm{Ni}$ et al. [12] proved that the AE frequency is less prone to attenuation with propagation distance than amplitude, many AE research works performed on composites confirmed that the AE frequency spectrum may be enough representative of damage mechanisms generating the $\mathrm{AE}$ signals. Usually, the lowest frequency ranges are ascribed to matrix cracking, intermediate-to interphase phenomena (fiber debonding and pull-out) while the highest originate in fiber failures [13]. Seen the complexity of the effects of experimental parameters on AE frequencies [6], there is still a need for broader confirmation of these relationships, examined in various testing set-ups, loading modes and in composites with different reinforcement architectures.

The time-to-failure under load is another critical damage descriptor of composites monitored by AE, determined mostly on the basis of source location functions [14]. With current accuracy of AE location ability not exceeding $2 \mathrm{~mm}$ [15], this methodology may be applicable to larger defects, like delamination or transverse cracks [5]. The complete time histories of damage processes in composites assessed with use of analytical techniques on $\mathrm{AE}$ data, require further confirmation by direct experimental techniques suitable for complete description of failure initiation processes in the range of microns, particularly matrix micro-cracking and fiber debonding [16].

Recently, studies on carbon fiber reinforced plastic (CFRP) composites have shown that the AE parameter named historic index (HI) may serve as an efficient experimental indicator of time of occurrence of fine damage initiation processes, including matrix micro-cracks and fiber debonding [17]. The HI indications registered during both monotonic and step-load bending tests of CFRP, also correlated well with clear scanning electron microscope (SEM) evidence showing such micro-defects [18]. Merging of steploading with $\mathrm{AE}$ and direct SEM observations enabled more accurate determination of load level at which the damage initiation processes occurred in the examined microstructures. With load interruption possible at any time/cycle/load level indicated by the AE HI, such experimental combination allowed for detailed microscopic (or other direct) observation and analysis of microstructural components where damage initiation occurred in micro-scale.

The aim of this study was to identify with use of AE HI parameter, the time of occurrence of damage initiation processes in glass fiber/epoxy resin composites of various fiber architectures and volume contents, subjected to monotonic and step-loading in bending. The research was also aimed at determining the type of micro-cracks formed at damage initiation in these composites and correlating microscopic (SEM) observations of defects with characteristics of $\mathrm{AE}$ signals registered during loading. The distinction of fiber/ matrix debonding in early AE signals determined by the AE HI readings is given particular attention in this study, as it is considered to be the principal mechanism of damage initiation in continuous glass fiber/epoxy resin matrix composites, contributing to formation of larger transversal cracks. To confirm, the values of AE waveform descriptor in form of rise time to amplitude ratio (R/A) were analyzed at points of time of damage initiation determined by $\mathrm{HI}$ in selected cycles of step-load bending tests of GFRP composites before rupture.

\section{Experimental}

The experimental procedures consisted of three blocks shown schematically in Fig. 1, with materials and data flow. All the necessary details are described in the text below.

\subsection{Materials}

The GFRP composites were fabricated as plates of dimensions $300 \times 200 \times 2 \mathrm{~mm}$ by hand lay-up method, according to light aviation industry standards. ${ }^{1}$ The quasi-unidirectional $\mathrm{E}$ glass-fiber fabric ${ }^{2}$ of density $223 \mathrm{~g} / \mathrm{m}^{2}$ was used as reinforcement. It is made of stronger warp yarns EC9-68 $\times 5 \mathrm{t} 0$ and sparse weft yarns EC7-22, maintaining shape of the fabric. The flexural modulus and flexural strength of quasi-unidirectional (UD or 1D) glass fabric in warp direction, as given by manufacturer are $37 \mathrm{GPa}$ and $810 \mathrm{MPa}$, respectively.

\footnotetext{
13 Xtrim Aircraft Factory, Bielsko-Biała, Poland.

2 Product 92,145 by P-D Interglas Technologies GmbH, 89,155 Erbach, Germany.
} 


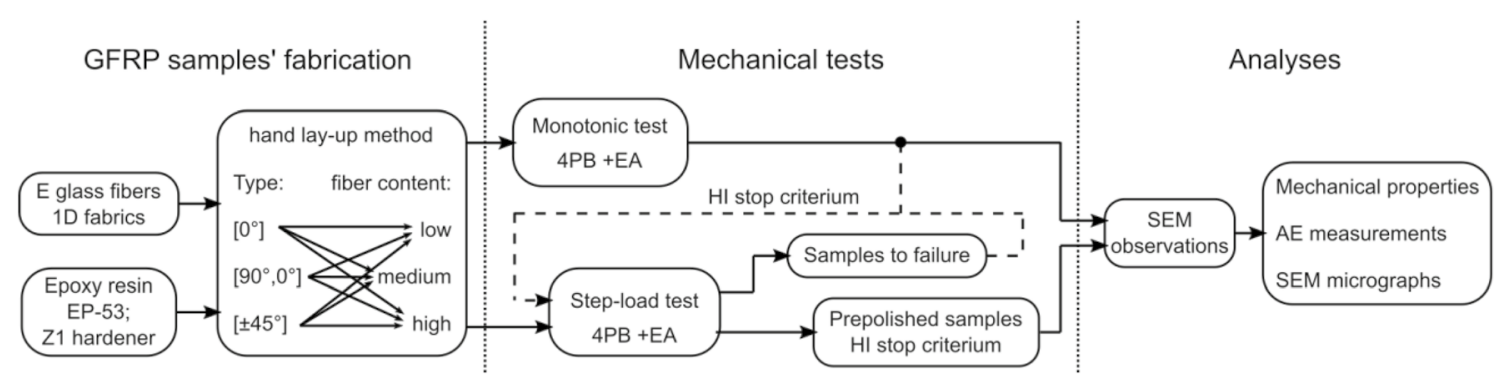

Fig. 1 The block scheme of experimental procedures used in this study

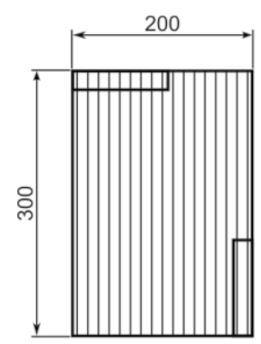

$1 \mathrm{D}$

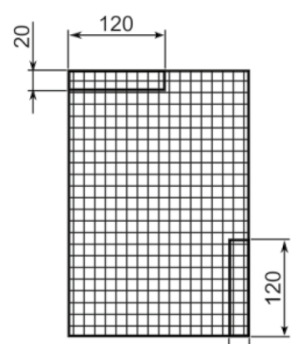

$[90,0] \rightarrow+20$

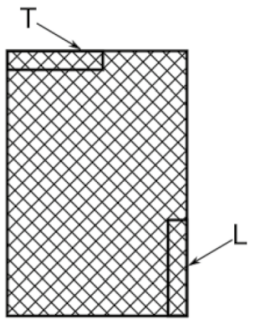

$[ \pm 45]$
Fig. 2 Fiber lay-up in the examined GFRP composites and the scheme of sample cutting for mechanical testing

The GFRP plates were prepared in three basic fiber configurations: quasi-unidirectional $\left[0^{\circ}\right]_{\mathrm{n}}$, cross-ply $\left[90^{\circ}, 0^{\circ}\right]_{\mathrm{n}}$ and angle-ply $\left[ \pm 45^{\circ}\right]_{n}$. The number of glass fabric layers and the amount of epoxy resin were purposely varied to give composites with different fiber volume contents (according to manufacturer): low $\sim 30 \%$, medium $\sim 40 \%$ and higher $\sim 50 \%$, respectively, for each fiber lay-up. The uneven number of glass fiber fabric plies ensured identical fiber lay-up on both bottom and top surface of each composite plate. To control closely the crack initiation [19] in quasi cross-ply composites [90,0], the warp yarns in bottom surfaces were always laid along shorter sides of composite plates.

The E glass-fiber fabric layers were embedded in mixture of epoxy resin with hardener ${ }^{3}$ and composite plates were cured in room temperature (RT) for $24 \mathrm{~h}$, covered with aluminium plates to obtain surface smoothness. The value of bending strength of hardened epoxy resin is given by manufacturer as $90 \mathrm{MPa}$. Rectangular samples of the size $120 \mathrm{~mm} \times 20 \mathrm{~mm} \times 2 \mathrm{~mm}$ were cut with diamond saw parallel (L) and perpendicular (T) to longer side of composite plates, as shown in Fig. 2.

\footnotetext{
${ }^{3}$ Resin Epidian EP 53, hardener Z-1 (mixing ratio 100:10,5), by Organika-Sarzyna, Ciech, Nowa Sarzyna, Poland.
}

\subsection{Mechanical and AE Examination}

The bending strength of GFRP composites was determined in monotonic 4-point bending tests using universal testing machine Instron (model 33R4467), with simultaneous monitoring of AE response of materials. The cross-head speed was $2 \mathrm{~mm} / \mathrm{min}$ and the inner/outer span of load points were $15 \mathrm{~mm}$ and $45 \mathrm{~mm}$, respectively (Fig. 3a). Five samples were examined in each of three types of composites (quasi 1D, cross-ply, angle ply),for each fiber volume content (low, medium, high) and cutting direction (L, T). All together 90 GFRP composite samples were tested in monotonic 4-point bending at room temperature $\left(23^{\circ} \mathrm{C}\right)$ and humidity of $55 \%$. Based on fracture load levels measured in monotonic tests, the load increments were defined accordingly for each material examined in step-load tests.

Step-loading was applied in a saw-tooth mode (Fig. 3b), with a sequence of loading and unloading [20]. Load increment was of the order of $15 \%$ of ultimate bending strength (Fsn) measured earlier in monotonic tests and was increased at average rate of $0.001 \mathrm{Fsn}$ per minute. Unloading rate was on average 0.1 Fsn per minute, down to the level not exceeding $1 \%$ of fracture stress, to prevent machine's instability. After each unload the hold period of $5 \mathrm{~min}$ was applied. This sequence was repeated till final failure of the sample, or until interruption of the test.

For increasing load tests in 4-point bending, three samples were selected in each GFRP composite type, fiber volume, and cutting orientation. One sample in each lot had its tensile surface (opposite to inner load points-Fig. 3a) pre-polished for microscopic (SEM) observations. Flexural step-load experiments were performed with similar inner/ outer spans as in monotonic tests, using the servo-hydraulic MTS 810 machine, equipped with force sensor MTS 661 19F-01 and FlexTest software, version 3.5B 1787.

Monitoring of damage initiation phenomena in real time during monotonic 4-point bending tests was performed using the AE Vallen system model AMSY6, ${ }^{4}$ equipped with Vallen

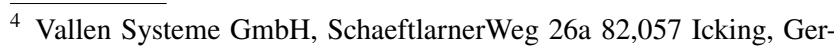
many.
} 


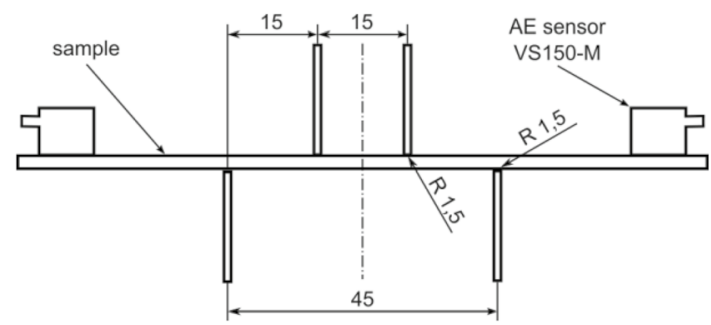

(a)

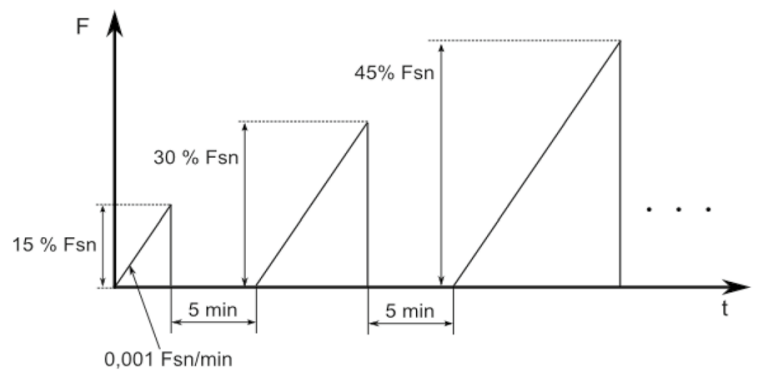

(b)

Fig. 3 a Experimental set-up for 4-point bending tests of GFRP with positioning of AE sensors, b loading schedule during flexural step-load tests

software for parametric and transient data acquisition and analysis. The AE signals were collected by Vallen resonant sensors V150-M placed on GFRP samples' ends (Fig. 3a), with surfaces covered with silicone grease and secured with scotch tape. The V150-M sensors embrace the frequency range from 100 to $450 \mathrm{kHz}$, the most important for capturing signals from AE events typical of micro-crack initiation in GFRP composites. The AE sensors were coupled through Vallen AEP3 preamplifiers to AE system with the signal threshold set to $40.7 \mathrm{~dB}$ and preamplifiers gain of $34 \mathrm{~dB}$. The AE duration discrimination time was set to $0.25 \mathrm{~ms}$, rearm time $0.41 \mathrm{~ms}$ and TR sample rate $5 \mathrm{MHz}$. Damage initiation processes during the step-load tests of GFRP samples were monitored with use of Vallen system model AMSY3, with similar V150-M resonant sensors, AEP3 preamplifiers and identical system settings. In both types of mechanical tests with assistance by acoustic emission, the standard AE signal calibration procedure using the Hsu-Nielsen source preceded the actual measurements [21].

\subsection{Microscopic (SEM) Observations}

All samples fractured in monotonic 4-pont bending tests had their fracture surfaces analyzed with high-resolution scanning electron microscope ${ }^{5}$ for details of state of damage. Selected samples with pre-polished side surfaces in each fiber lay-up and volume content examined in step-load tests had their loading interrupted after significant increase of the AE HI parameter. Their tensile in bending surfaces (see Fig. 3a) were subjected to detailed SEM analyses for presence of micro-cracks. All scanning electron microscope examinations were carried out on uncoated samples' surfaces observed in secondary electron mode under low vacuum $(60 \mathrm{~Pa})$ and at low voltage $(5 \mathrm{kV})$.

\footnotetext{
5 Nova NanoSEM 200,FEI Company, Europe NanoPort, Achtseweg Noord 5, 5651 GG Eindhoven, The Netherlands.
}

\section{Results}

In this section, the results of mechanical properties' examination obtained in monotonic and step-load tests are correlated with the results of acoustic emission measurements, and then verified by direct SEM observations on samples' fracture and tensile surfaces.

\subsection{Mechanical Properties of GFRP Composites in Bending}

Figure $4 \mathrm{a}$ presents the values of bending fracture stress of examined GFRP composites in function of fiber volume content and lay-up. The strength of unidirectional (1D) GFRP samples cut from composite plates along their longer side, i.e. following stronger warp glass fibers (denominated L), grows with increasing fiber volume fraction, according to general "rule of mixtures" [1]. The strength of samples cut along shorter side of composite plates, i.e. vertically to fibers (T), is not affected by increasing fiber volume content, as it depends only on interphase properties [22].

Figure $4 \mathrm{~b}$ shows typical force increases registered during step-loading cycles of the examined GFRP composites together with simultaneous readings of the AE (HI) parameter, which allowed for control and interruption of step-test after significant (i.e. $>1,4$ ) increase of HI [20].

\subsection{Damage in 1D GFRP Samples Cut Vertical to Fibers [90]}

The AE frequencies for maximum amplitude $(\mathrm{FmA})^{6}$ obtained during monotonic tests of low fiber content GFRP samples cut transversally ( $\mathrm{T}$ type), indicate fiber/matrix interphase debonding $(\sim 200 \mathrm{kHz})$, possibly together [8] with matrix micro-cracking $(\sim 150 \mathrm{kHz})$, as dominant damage initiation mechanisms (Fig. 5a).

\footnotetext{
${ }^{6}$ Analysis with use of FFT software by Vallen Systeme GmbH.
} 


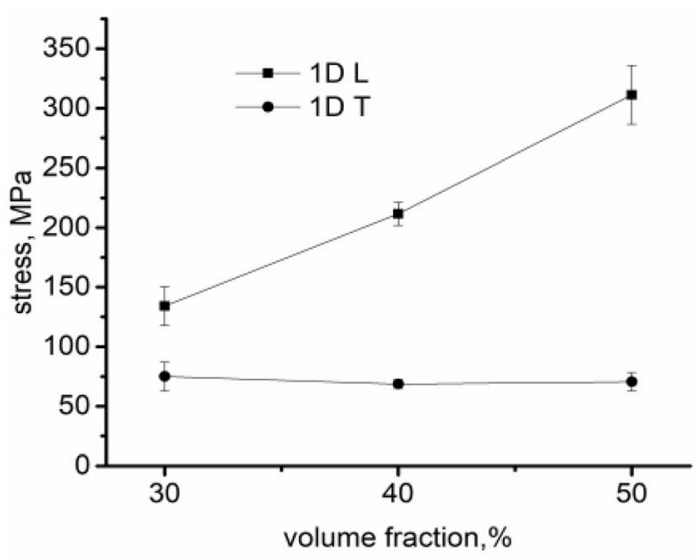

(a)
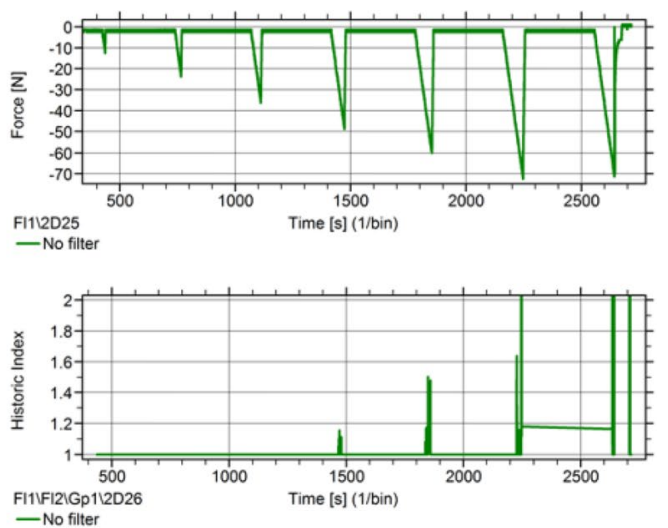

(b)

Fig. 4 a The 4-point bending strength of 1D GFRP in function of fiber volume, b flexural step-load increase in bending of composite (top) and resulting variations of historic index (bottom)
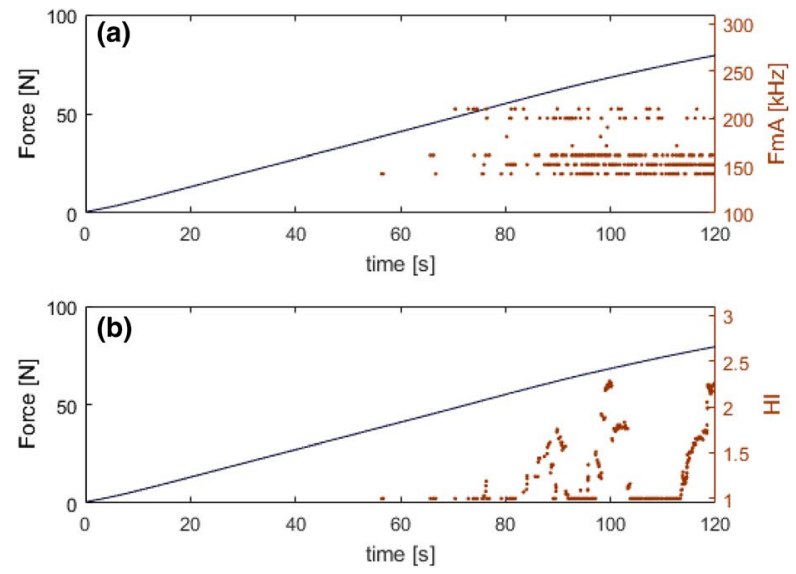

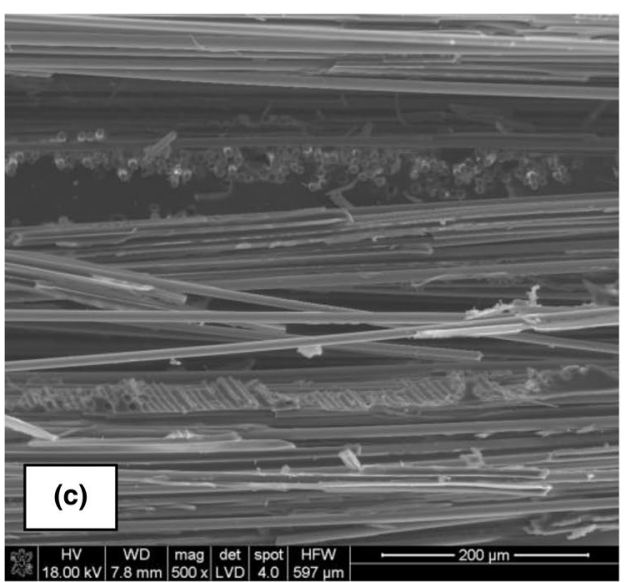

Fig. 5 a The AE frequency (FmA) distribution of AE in 1D GFRP type T sample with low fiber content (30\%) subjected to monotonic bending, $\mathbf{b}$ increases of AE HI with time of test and $\mathbf{c}$ debonding in longitudinal warp yarns and broken fibers of binding weft strands, seen in SEM

Debonding is also dominant in SEM observations of fracture surfaces (Fig. 5c), for this particular fiber lay-up, showing clear surfaces of warp fibers. The exact time of damage initiation in monotonic tests is indicated by a noticeable increase of AE HI, as seen in Fig. 5b ( $90 \mathrm{~s})$.

Figure 6a shows incremental growth of the number of AE hits during last three cycles of step-load test before failure of 1D GFRP transversal sample (T type) with low fiber volume. Figure $6 \mathrm{~b}$ compares the data of AE HI readings (left axis) for this sample with increases of AE rise time/amplitude ratio (R/A-right axis) occurring at the same time ( $\pm 1 \mathrm{~s}$.) as HI maximums in each of these loading cycles.

The AE HI readings in both monotonic and step-load tests of GFRP composites were obtained directly through Vallen software. The values of AE rise time/amplitude ratio (R/A) in step-load tests were calculated for each hit during loading and processed by floating averaging within 1 s span. In all other (than shown in Fig. 6) step-load tests of transversely cut 1D GFRP composites with varying fiber volume, the increases of AE R/A parameter correlated well with registered $\mathrm{HI}$ patterns in a similar way, i.e. within a narrow time window of $\pm 1 \mathrm{~s}$.

\subsection{Damage in 1D GFRP Samples Cut Longitudinally to Fibers [0]}

Fiber breaks in 1D GFRP [0] longitudinal samples (cut along warp fibers - type L) show much stronger effects on AE frequency data obtained during monotonic bending tests, as shown in Fig. 7a for sample with higher fiber volume (50\%).

As fiber breaks in composites are always accompanied by debonding and pull-out [9], larger contribution of interphase damage is also shown in Fig. 7a. The presence of debonding 

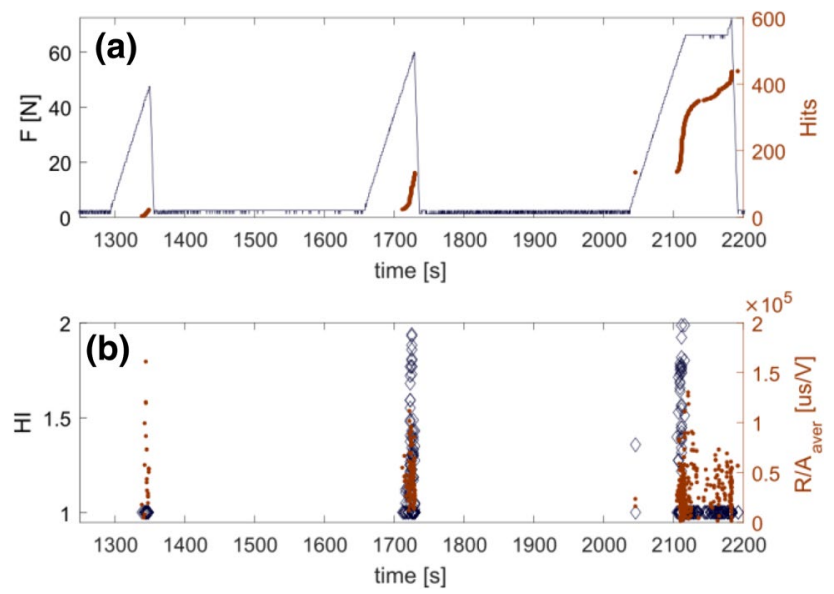

Fig. 6 a Increases of force applied and registered AE hits number with time of step-load test of transversal (T type) sample of 1D GFRP with low fiber volume fraction (30\%), b the values of AE HI and R/A parameters during these last three step-load cycles

can be observed directly in fracture surface of 1D GFRP [0] longitudinal sample shown in Fig. 7c. Significant increases of AE HI parameter (Fig. 7b) confirm that in these higher strength GFRP samples damage initiates already in the midtime of monotonic loading, accompanied by a visible loss of stiffness.

\subsection{Damage Initiation in Cross-ply $[90,0]$ GFRP Samples}

Figure 8 summarizes typical mechanical, acoustic emission and microscopic data obtained for L type samples of cross-ply [90,0] GFRP composite during monotonic 4-point bending test. The measured values of AE frequency (FmA) shown in Fig. 8a reveal the interphase debonding and also matrix micro-cracking as dominant mechanisms of damage initiation. Increases of AE HI during bending shown in Fig. $8 \mathrm{~b}$ indicate the timing of damage initiation. The fracture surface observed in SEM after monotonic test (Fig. 8c) informs of the state of the sample after rupture, with no leads concerning the sequence of damage. However, the presence of crack shown in SEM picture of tensile surface of the sample examined after interrupted step-load cycling (Fig. 8d), confirms that fiber debonding contributes to damage initiation in this material, macroscopically still carrying the load.

These observations are consistent with AE results obtained during step-load tests. Figure 9a indicates typical for interphase phenomena values of $\mathrm{AE}$ frequency (FmA) registered during last 4 cycles of step-load bending test of L type GFRP [90,0] sample, with glass fiber warp yarns perpendicular to tensile stress on the outer surface.

Figure $9 \mathrm{~b}$ shows the values of AE R/A parameter (right axis) registered in these tests and overlapping the $\mathrm{AE} \mathrm{HI}$ values (left), which may be indicative of strong contribution of fiber debonding to formation of transverse cracks in the examined GFRP composites.

\subsection{Damage Initiation in Angle-ply [ \pm 45] GFRP Composites}

The failure of angle-ply GFRP composites examined in both monotonic and cyclic step-load tests generated only a small amount of acoustic emission signals registered with

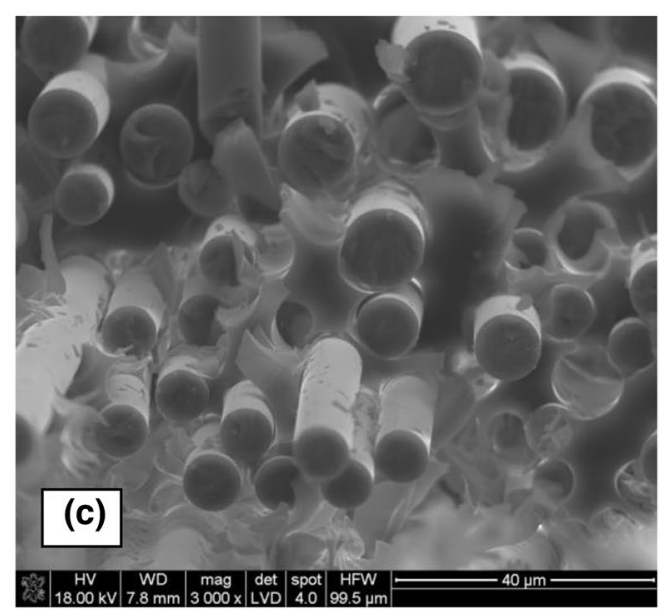

Fig. 7 a The AE frequency (FmA) of 1D longitudinal (type L) sample with higher fiber volume (50\%), b increases of AE HI with time of bending test of 1D [0] GFRP sample (type L), $\mathbf{c}$ SEM of fracture surface of 1D [0] GFRP composite ruptured in monotonic 4-point bending 

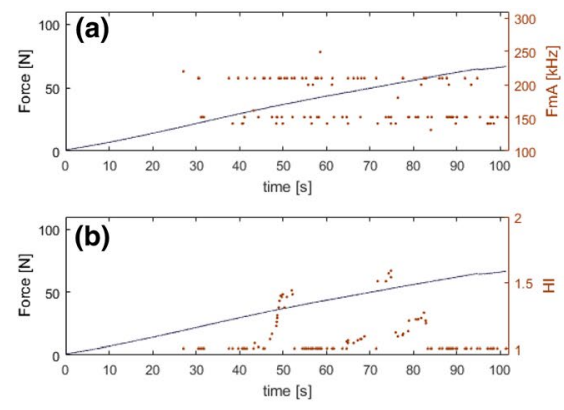
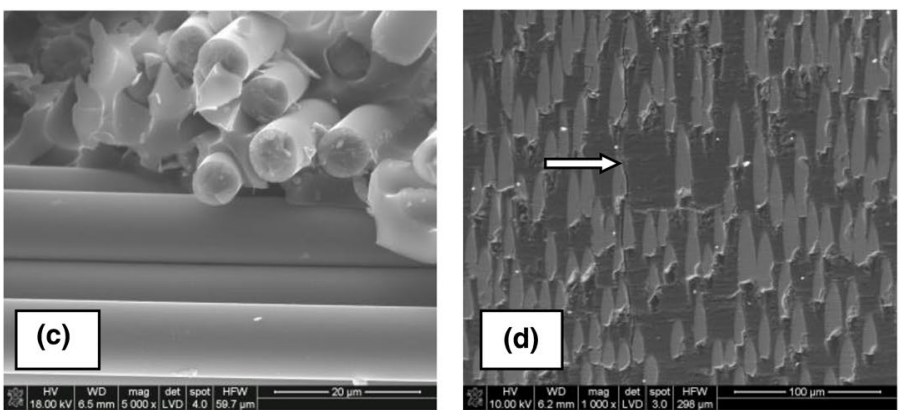

Fig. 8 a The AE frequency (FmA), and b AE HI of [90,0] GFRP laminate in monotonic bending, $\mathbf{c}$ SEM of fracture surface of [90,0] GFRP ruptured in monotonic test (average fib. vol. 40\%), d debonding crack in warp yarn on tensile surface of [90,0] GFRP sample (aver. fib. vol. 40\%)
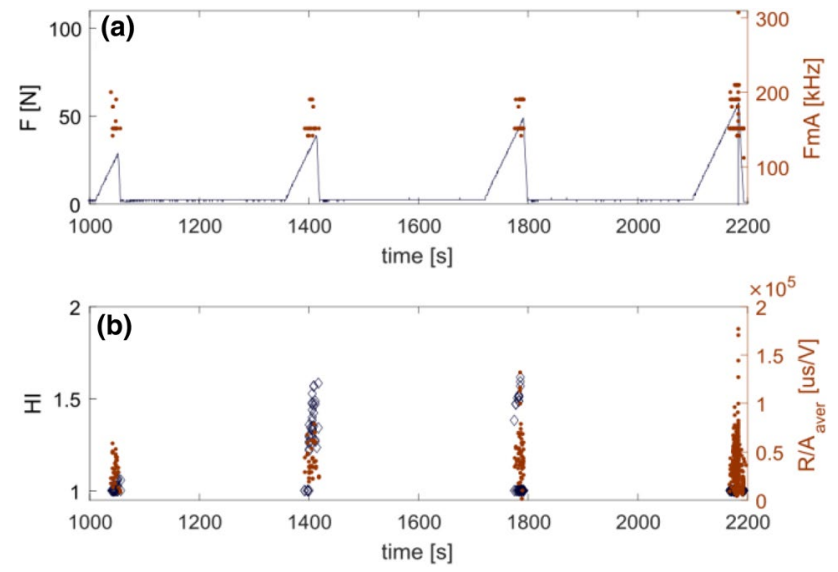

Fig. 9 a The AE frequency (FmA) during step-loading sequence of $\mathrm{L}$ type GFRP $[90,0]$ sample, $\mathbf{b}$ the indications of AE R/A and HI parameters during the last four cycles of step-load test equipment settings used. Figures 10a and 11a confirm that the AE frequencies (FmA) in 4-point bending monotonic and step-load tests were dominated by interphase and matrix damage. The AE HI increase in monotonic tests (Fig. 10b) indicates damage initiation signals near $70 \%$ of loading time.

As can be seen in Fig. 11b below, the AE R/A ratio increases (right axis) measured in step-load tests of angleply composites also overlap the values of AE HI (left). Both these AE parameters correlate well with microscopic (SEM) observations of side surfaces after interruption of step-loading (Fig. 10d), confirming that debonding cracks contribute substantially to damage initiation in GFRP angle-ply composites.
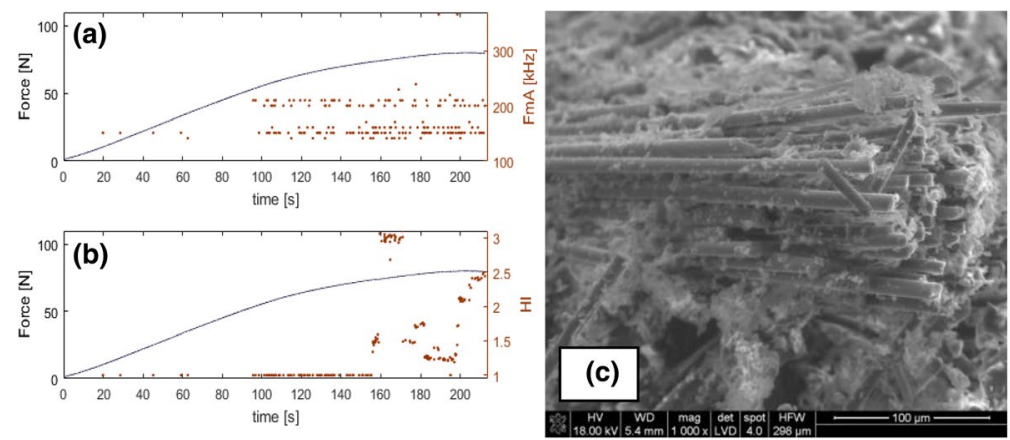

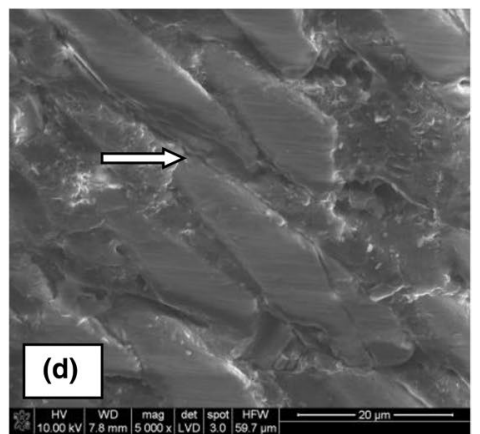

Fig. 10 a The AE frequency (FmA) and $\mathbf{b}$ historic index of angle-ply GFRP laminate of average fiber content (40\%) in monotonic bending, $\mathbf{c}$ SEM of fracture surface of angle-ply GFRP, $\mathbf{d}$ debonding crack on side surface of angle-ply GFRP sample with average fiber content (40\%) after interrupted step-load 

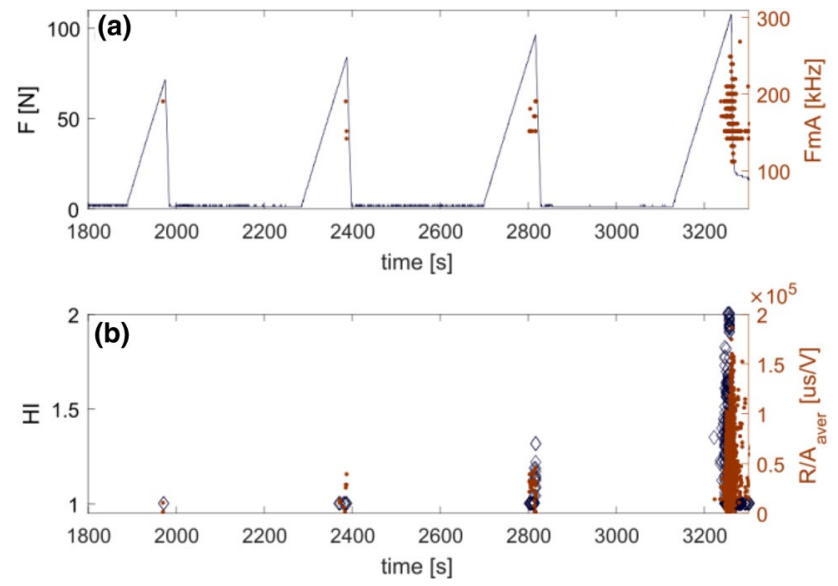

Fig. 11 a Step-load curve and AE frequency (FmA) indications observed in angle-ply GFRP, $\mathbf{b}$ the AE parameters R/A: (right axis) and HI (left) in angle-ply GFRP composite

\section{Discussion}

The experimental materials in this study were processed in such a way, that all cross-ply GFRP composites had their warp fiber yarns laid along shorter side of fabricated plates. For this reason the $\mathrm{T}$ type samples of cross-ply composites had their bending strength increasing with increasing fiber volume (compare Figs. 2 and 4a), inversely to 1D samples. The cross-ply samples cut longitudinally to larger plate side (type L) showed low and constant strength, of the order comparable to their interlaminar shear strength (ILSS), irrespective of fiber volume [22].

Step-load tests of GFRP composites were performed here primarily to control (with use of $\mathrm{AE}$ ) the process of microcrack initiation in these materials and the load level at which it occurs, as shown in Fig. 3b. It has been described in earlier works [23] that during the tensile tests of composites the micro-crack initiation may occur in the entire volume of the sample under stress, including large side surfaces. Preparation of surfaces and detailed SEM analyses of large scale samples could be difficult. time consuming and costly. Other known direct NDE techniques like C-scan or X-ray inspection do not have sufficient accuracy (measurable in micrometers) as compared to SEM [9]. During bending tests of materials the damage in form of micro-cracks most likely initiates in the area of maximum stress on the outer surface of bent sample. In most cases of 4-point bending tests damage should become visible within the area between the inner load points. Such a limited area can be easily inspected with sufficient accuracy using the high-resolution SEM.

In both monotonic and step-load tests of composite samples with transversal warp fibers (1D type $\mathrm{T}$ and cross-ply $\mathrm{L}$ samples), the $\mathrm{AE} \mathrm{HI}$ increases indicated points of time of damage initiation (Figs. 5b, 8b), while the AE frequencies confirmed debonding as dominant damage mechanism in these materials. Since the appearance of AE R/A ratio values (Figs. 6b, 9b) is considered indicative of the presence of transversal cracks in composites [5], the fiber debonding may be regarded as contributing to initial stage of transversal cracks formation, not quite in agreement with earlier analytical models [24]. With no delaminations observed in the examined GFRP cross-ply materials, thus no visible transition to mode II fracture [5] in this early damage stage, the registered here increases of AE R/A parameter can be related only to debonding crack growth and coalescence. The $\mathrm{AE}$ indications have direct confirmation in SEM observations (Fig. 8d), and they are consistent with earlier findings related to fiber debonding [18].

In GFRP composite samples with longitudinal fibers, thus with higher bending strength, the first damage of fibers misaligned or overstrained by manufacturing process may occur relatively early during loading, while the majority of fibers still carry the load [25]. This description refers also to 1D type L samples examined here, and it is confirmed by the registered changes of $\mathrm{AE} \mathrm{HI}$ with time of monotonic bending test (Fig. 7b). The HI parameter shows significant increases $(>1,4)$ near the middle of monotonic loading time ( $100 \mathrm{~s}$ and $115 \mathrm{~s})$, followed by visible loss of stiffness at $\mathrm{HI} \sim 7$ and further damage $>170 \mathrm{~s}$. Much higher AE HI values, measured in dozens, have been reported at appearance of large transversal cracks preceding failure of composites examined in bending [26].

As confirmed by results presented in Sect. 3.5 above, the final damage in angle ply composites occurs mostly by interphase phenomena. Macroscopically the angle-ply composites are characterized by large fracture strains in bending and their apparent behaviour under stress resembles that of visco-elastic materials, despite the fact that they are made of identical brittle components as much stiffer 1D or cross-ply composites examined here. Under load the angle-ply composites develop large number of micro-cracks [28], including debonding described in this work (Fig. 10b). These defects contribute to loading hysteresis [27] and to significant increase of fracture energy of these materials, so relevant to construction applications [28].

Experimental evidence shown in this work demonstrates debonding as dominant mechanism of damage initiation in composite laminae with off-line fibers. Bailey et al. [29], who were probably the first to describe in detail the transversal cracks in FRP composites, never called them "matrix cracks", and presented clear SEM micrographs showing mostly debonding cracks (see Fig. 7b in Ref. [29]). For unknown reasons, in analytical works of the $80 \mathrm{~s}$ [30] such transversal cracks were renamed into "transversal matrix cracks" with no adequate experimental confirmation. Studies applying acoustic emission in the 90 s, e.g.[31], also repeated the term "transversal matrix cracks" although the 
SEM picture presented as prove showed clearly debonding cracks (compare Fig. 6 in Ref. [31]). The synonymous meaning was reinforced further [24], by analytical model of matrix macro-crack propagating uniquely within the matrix material between the off-line fibers (see Fig. 3 in Ref. [24]). Quite recent works still use the name "transversal matrix cracks" for this feature, while they present clear SEM evidence of debonding cracks (see Fig. 5b in Ref. [32].). It is worthy to note here that the width of epoxy resin microcracks is near the order of magnitude smaller than typical transversal cracks [8].

In attempts of clarification of damage initiation process in fibrous composites, contemporary experimental results obtained on CFRP with model fiber architectures also point at coalescence of interphase defects in form of fiber/matrix debonding, as dominant damage initiation mechanisms in epoxy matrix composites with fibers oriented transversely, i.e. $\left[90^{0}\right]$ to load axis [18].The application of quite different methodology (electrical conductivity) by Li et al. [33] lead to identical conclusions concerning damage initiation and progress in woven glass fiber/epoxy composites, additionally confirmed by excellent microscopic evidence. Figure 7 in Ref. [33] proves that damage in FRP composites initiates by coalescence of matrix micro-cracking and fiber debonding, and than through formation of larger transverse cracks leads to final delaminations.

Inevitably, enhancing the resolution of novel NDE techniques, like computer tomography [34], should help unveiling the time-related details of damage initiation processes in fiber composites, so critical for their structural health monitoring and also for use of self-healing technologies.

\section{Conclusions}

- The results of this work confirmed that the acoustic emission parameter named historic index may serve as an accurate and reliable indicator of the time of occurrence of micro-damage initiation in fiber-epoxy composites subjected to bending

- Presented here microscopic evidence correlated well with the acoustic emission frequency and historic index indications. These data proved that fiber-matrix debonding was a dominant mechanism of damage initiation in bending of the examined glass-epoxy composites with different architectures and fiber contents

- The compliance of the acoustic emission historic index with the rise time/amplitude ratio data observed in step-load tests may be indicative of the coalescence of debonding defects as the origin of transversal cracks formation observed in further damage development.
Acknowledgements The experimental part of this work was financially supported by National Science Centre, Poland, NCN Grant \#2011/03/B/ST5/03180. Authors extend their thanks to Dr. M. Ziabka of AGH University of Science and Technology, Krakow, Poland, for excellence in SEM analyses, and to Mr. B. Kotecki of AGH University of Science and Technology, Krakow, Poland, for careful sample preparation for microscopic observations. Mr. T. Spodaryk and Mr. M. Suchon of Bosmal, Bielsko-Biala, Poland, assisted in monotonic mechanical and AE tests. Thanks also go to Mrs. E. Mrowiec of ATH University of Bielsko-Biala for dedicated help in bibliographic search throughout the study.

Data Availability All data generated or analysed during this study are included in this published article.

\section{Compliance with Ethical Standards}

Conflict of interest The authors declare that they have no conflict of interest.

Open Access This article is licensed under a Creative Commons Attribution 4.0 International License, which permits use, sharing, adaptation, distribution and reproduction in any medium or format, as long as you give appropriate credit to the original author(s) and the source, provide a link to the Creative Commons licence, and indicate if changes were made. The images or other third party material in this article are included in the article's Creative Commons licence, unless indicated otherwise in a credit line to the material. If material is not included in the article's Creative Commons licence and your intended use is not permitted by statutory regulation or exceeds the permitted use, you will need to obtain permission directly from the copyright holder. To view a copy of this licence, visit http://creativecommons.org/licenses/by/4.0/.

\section{References}

1. Kelly, A., Zweben, C. (eds.): Comprehensive Composites. Elsevier, Oxford (2001)

2. Kempf, M., Skrabala, O., Altstadt, V.: Acoustic emission analysis for characterisation of damage mechanisms in fiber reinforced thermosetting polyurethane and epoxy. Compos. Part B 56, 477483 (2014)

3. Lomov, S.V., Ivanov, D.S., Truong, T.C., Verpoest, I., Baudry, F., Bosche, K.V., Xie, H.: Experimental methodology of study of damage initiation and development in textile composites in uniaxial tensile test. Compos. Sci. Technol. 68(12), 2340-2349 (2008)

4. Gorman, M.R.: Acoustic emission in structural health monitoring (SHM). In: Boller, C., et al. (eds.) Encyclopedia of Structural Health Monitoring, pp. 79-100. Wiley, New York (2009)

5. Aggelis, D.G., Barkoula, N.M., Matikas, T.E., Paipetis, A.S.: Acoustic structural health monitoring of composites: damage identification and evaluation in cross ply laminates using acoustic emission and ultrasonics. Compos. Sci. Technol. 72(10), 1127$1133(2012)$

6. Awerbuch, J., Leone, F.A., Ozevin, D., Tan, T.M.: On the applicability of acoustic emission to identify modes of damage in fullscale composite fuselage structures. J. Compos. 50(4), 447-469 (2016)

7. Konsztowicz, K., Nowak, M., Baran, I., Ziąbka, M., Chlopek, J.: Detection of micro-crack initiation in epoxy matrix material 
with use of acoustic emission. Pap 3.01-07 In: Proceeding of the ECCM17, Munich (2016)

8. Baker, C., Morscher, G.N., Pujar, V.V., Lemanski, J.R.: Transverse cracking in carbon fiber reinforced polymer composites: modal acoustic emission and peak frequency analysis. Compos. Sci. Technol. 116, 26-32 (2015)

9. Ono, K., Gallego, A.: Research and Applications of AE on Advanced Composites. In: 30th European Conference on Acoustic Emission Testing \& 7th International Conference on Acoustic Emission, University of Granada (2012)

10. Huguet, S., Godin, N., Gaertner, R., Salmon, L., Villard, D.: Use of acoustic emission to identify damage modes in glass fiber reinforced polyester. Compos. Sci. Technol. 62(10-11), 1433-1444 (2002)

11. Sause, M.G.R., Gribov, A., Unwin, A.R., Horn, S.: Pattern recognition approach to identify natural clusters of acoustic emission signals. Pattern Recogn. Lett 33, 17-23 (2012). https://doi. org/10.1016/j.patrec.2011.09.018

12. Ni, Q.Q., Kurashiki, K., Iwamoto, M.: AE technique for identification of micro failure modes in CFRP composites. Mater. Sci. Res. Int. 7(1), 67-71 (2001)

13. Sajith, S., Arumugam, V., Santulli, C.: Failure mode discrimination in mode II fracture of glass/epoxy laminates using acoustic emission technique. Mater. Sci. Eng. Adv. Res 1(2), 16-25 (2015)

14. Hamstad, M.A., O'Gallagher, A., Gary, J.: Examination of the application of a wavelet transform to acoustic emission signals: part 2 source location. J. Acoust. Emiss. 20, 62-81 (2002)

15. Scholey, J.J., Wilcox, P.D., Wisnom, M.R., Friswell, M.I.: Quantitative experimental measurements of matrix cracking and delamination using acoustic emission. Compos. Part A 41(5), 612-623 (2010)

16. Bai, F., Gagar, D., Foote, P., Zhao, Y.: Comparison of alternatives to amplitude thresholding for onset detection of acoustic emission signals. Mech. Syst. Signal Process. 84, 717-730 (2017)

17. Baran, I.J., Nowak, M.B., Chlopek, J.P., Konsztowicz, K.J.: Acoustic emission from micro-crack initiation in polymer matrix composites in short beam shear test. J. Nondestruct. Eval. 37(1), 7 (2018)

18. Panek, M., Nowak, M., Baran, I., Konsztowicz, K.J.: Acoustic Emission Detection of Damage Initiation in 1D CFRP NCF Composites Subjected to Bending. In: 32nd European Conf. on Acoustic Emission Testing EWGA, Prague, Czech Rep. paper 393 (2016)

19. Smith, P.A., Boniface, L., Glass, N.F.C.: A comparison of transverse cracking phenomena in $(0 / 90)_{(\mathrm{s})}$ and $(90 / 0)_{(\mathrm{s})}$ CFRP laminates. Appl. Compos. 5(1), 11-23 (1998)

20. ASTM E2478-11.: Standard Practice for Determining DamageBased Design Stress for Glass Fiber Reinforced Plastic (GFRP) Materials Using Acoustic Emission. ASTM International, West Conshohocken (2011)

21. Hsu, N.N., Breckenridge, F.R.: Characterization and calibration of acoustic-emission sensors. Mater. Eval. 39(1), 60-68 (1981)
22. Baley, C., Grohens, Y., Busnel, F., Davies, P.: Application of interlaminar tests to marine composites: relation between glass fiber/polymer interfaces and interlaminar properties of marine composites. Appl. Compos. 11(2), 77-98 (2004)

23. Li, L., Lomov, S.V., Yan, X., Carvelli, V.: Cluster analysis of acoustic emission signals for $2 \mathrm{D}$ and $3 \mathrm{D}$ woven glass/epoxy composites. Compos. Struct. 116, 286-299 (2014)

24. Cuntze, R.G., Freund, A.: The predictive capability of failure mode concept-based strength criteria for multidirectional laminates. Compos. Sci. Technol. 64(3-4), 343-377 (2004)

25. Vassilopoulos, A.P., Keller, T.: Fatigue of Fiber-Reinforced Composites. Springer, London (2011)

26. Ativitavas, N.:Acoustic emission signature analysis of failure mechanisms in fiber reinforced plastic structures, $\mathrm{PhD}$ Dissertation, University of Texas, Austin (2002)

27. Nowak, M., Baran, I., Konsztowicz, K.J.: Acoustic emission from unilateral bending of large CFRP plates. Progres in Acoustic Emission XIX, (pp. 71-76), In: The Japanese Society for NDI, the 24th Int. Acoustic Emission Symposium, Sapporo (2018)

28. Piekarczyk, J., Piekarczyk, W., Blazewicz, S.: Compression strength of concrete cylinders reinforced with carbon fiber laminate. Constr. Build. Mater. 25(5), 2365-2369 (2011)

29. Bailey, J.E., Curtis, P.T., Parvizi, A.: Transverse cracking and longitudinal splitting behavior of glass and carbon-fiber reinforced epoxy cross ply laminates and the effect of poisson and thermally generated strain. Proc. R. Soc. Lond. Ser. A 366(1727), 599-623 (1979)

30. Wang, A.S.D., Chou, P.C., Lei, S.C.: A stochastic-model for the growth of matrix cracks in composite laminates. J. Compos. 18(3), 239-254 (1984)

31. Prosser, W.H., Jackson, K.E., Kellas, S., Smith, B.T., McKeon, J., Friedman, A.: Advanced wave-form-based acoustic-emission detection of matrix cracking in composites. Mater. Eval. 53(9), 1052-1058 (1995)

32. Majid, M.S.A., Afendi, M., Daud, R., Gibson, A.G., Assaleh, T.A., Hale, J.M., Hekman, M.: Acoustic emission monitoring of multiaxial ultimate elastic wall stress tests of glass fiber-reinforced epoxy composite pipes. Adv. Compos. 24(1), 1-16 (2015)

33. Li, W.K., He, D.L., Dang, Z.M., Bai, J.B.: In situ damage sensing in the glass fabric reinforced epoxy composites containing CNT$\mathrm{Al}_{2} \mathrm{O}_{3}$ hybrids. Compos. Sci. Technol. 99, 8-14 (2014)

34. Yu, B., Blanc, R., Soutis, C., Withers, P.J.: Evolution of damage during the fatigue of $3 \mathrm{D}$ woven glass-fiber reinforced composites subjected to tension-tension loading observed by time-lapse X-ray tomography. Compos. Part A 82, 279-290 (2016)

Publisher's Note Springer Nature remains neutral with regard to jurisdictional claims in published maps and institutional affiliations. 